\title{
Reply to the letter concerning article: 'Cervical necrotizing fasciitis: descriptive, retrospective analysis of 59 cases treated at a single center'
}

\author{
Johanna Elander ${ }^{1} \cdot$ Michael Nekludov $^{2}$ - Agneta Larsson ${ }^{2,5} \cdot$ Britt Nordlander $^{3}$ • \\ Staffan Eksborg ${ }^{4}$ Jonas Hydman ${ }^{3}$
}

Received: 22 January 2017 / Accepted: 23 January 2017 / Published online: 4 March 2017

(C) Springer-Verlag Berlin Heidelberg 2017

\section{Dear Editor,}

We agree that in the clinical situation where cervical necrotizing fasciitis is under consideration, the most important diagnostic tool is immediate CT scan covering the neck and thorax. However, in the case where radiological signs are missing or not conclusive, the infection may still develop into fulminant fasciitis (i.e., the sensitivity is rather low in the early phase of the disease). Therefore, the clinical status of the patient should be monitored carefully in this initial phase. When the diagnosis cannot be ruled out, surgical intervention is recommended as soon as possible.

Kind regards,

Johanna Elander, MD.

This reply refers to the article available at doi:10.1007/s00405017-4478-y.

Johanna Elander

Johannaelander78@gmail.com

1 Department of Otorhinolaryngology, Region Gotland, Visby Lasarett, Visby, Sweden

2 Department of Anaesthesia, Surgical Services and Intensive Care, Karolinska University Hospital, Stockholm, Sweden

3 Department of Otorhinolaryngology, Karolinska University Hospital, Stockholm, Sweden

4 Department of Women's and Children's Health, Karolinska Institutet, Stockholm, Sweden

5 Department of Physiology and Pharmacology, Karolinska Institutet, Stockholm, Sweden 